\title{
PREDETERMination OF THE UnCERTAinTY BUdGet AND ERROR ANALYSIS OF THE PHOTOGRAMMETRIC METHOD IN HEAVY MACHINERY
}

\author{
Miroslav Leventov Kokalarov, \\ "Angel Kanchev" University of Ruse, the city of Ruse, Republic of Bulgaria.
}
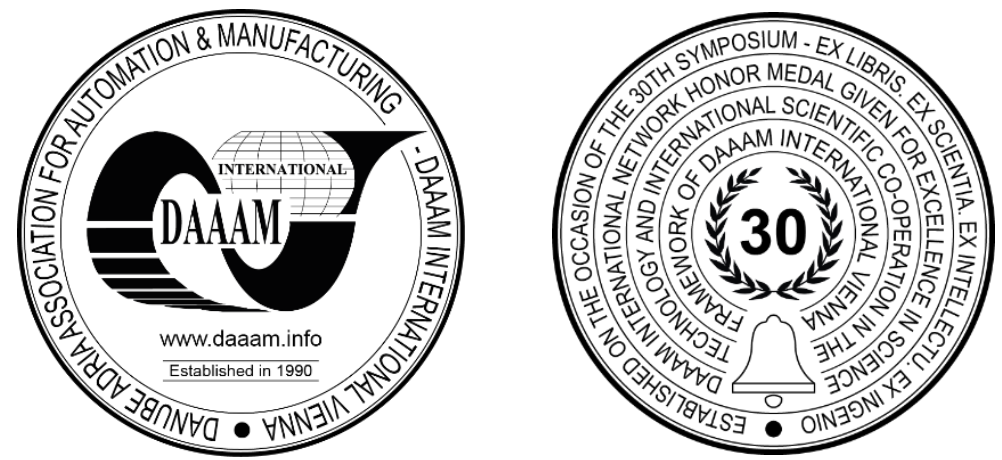

This Publication has to be referred as: Kokalarov, M[iroslav] (2019). Predetermination of the Uncertainty Budget and Error Analysis of the Photogrammetric Method in Heavy Machinery, Proceedings of the 30th DAAAM International Symposium, pp.0914-0920, B. Katalinic (Ed.), Published by DAAAM International, ISBN 978-3-902734-22-8, ISSN 1726-9679, Vienna, Austria

DOI: $10.2507 / 30$ th.daaam.proceedings.127

\begin{abstract}
The report examines the major sources of uncertainty in the Photogrammetric Measurement Method and their application in heavy machinery using free software. This article aims to highlight the major differences between measurement error and uncertainty, as well as to determine the true difference between the uncertainty budget using the photogrammetric method of measurement in small and very small sizes (about and less than $2 \mathrm{~mm}$ ) and these sizes that are widespread in the heavy machinery industry.
\end{abstract}

Keywords: Uncertainty; Photogrammetric method; Measurement error; Orthotropic surfaces.

\section{Introduction}

When performing their daily tasks, technologists, designers and quality engineers, knowing the specifics of heavy machinery, realize that technical quality control is extremely important in every technological stage of mechanical engineering. One of the most commonly controlled parameters in heavy engineering is the deviation of the linear and angular dimensions, the shape (the macrogeometry) and the location of the constituent parts in the article.

Measurement is a set of actions that are intended to determine the value of a measured value.

Measurement accuracy is determined both by measurement errors and by the uncertainty of the result obtained by the random influence of various factors. When estimating the uncertainty of contact measurement methods, standard methodologies may be used, which are missing from contactless measurements [2].

All measurements are subject to error, so the result of a single measurement is different from the true value of the measured value. By investing time and resources, most sources of measurement error can be identified, errors can be evaluated and adjusted accordingly, for example by calibration. Rarely, however, are time and resources available to identify and fully correct them [2].

The presentation of the measurement result by measurement error is effective when there is a standard or other source presenting with some accuracy the true value of the measured value and thus the possibility of estimating the error [3]. 
In the absence of information about the true value of a quantity, its estimation in the measurement process can be determined to an accuracy only up to the magnitude of one interval, at which it can be expected with certain certainty that the true value will appear - the so-called the uncertainty of the result [2].

\section{Theoretical justification}

\subsection{Errors when measuring the controlled size depending on the parameters of the measured object.}

The formation of an outline image description can be obtained except by segmenting the image field into areas and by defining the outlines in the image. It is based on the assumption that the individual areas are separated by a stronger or less pronounced border, on either side, where there is a sharp change in the image parameters (for example, light-dark). This change can also be reflected in a change in the average gray level or in statistical parameters describing texture areas in color. The outline represents the line in which this parameter change occurs. Depending on the nature of this change, edges or an area where the edge is contained are observed. The edge represents the boundary on which there are areas with different properties on both sides.

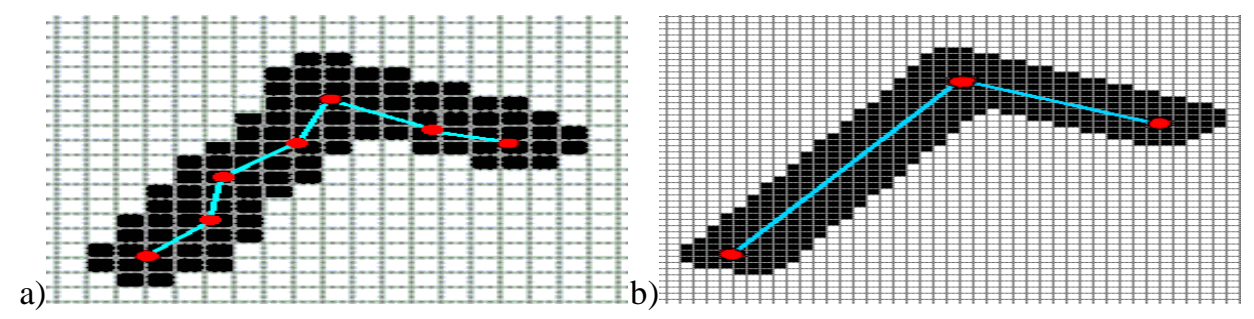

Fig. 1. Outline image formation - a) real, b) perfect.

This change in characteristics, considered perpendicular to the boundary line, is approximated by a sharp step transition (two adjacent pixels ideally) or a smooth transition (minimum three pixels ideally). The absence of sharp edges (the presence of rounding radii and relatively large ones) at the edges of the surface whose size is sought would further aggravate the situation - Fig. 1. If this situation is combined with the presence of poor focusing in the plane of measurement, with vignetting, spherical and chromatic aberrations, and the coma then the situation becomes catastrophic - figure 1-a.

Fujifilm digital camera is used for photography. The resolution used for the photos is $5 \mathrm{Mpx}(2592 / 1944$ px), with a conditional size of one "real" pixel of $3.1 \mu \mathrm{m}$.

From the experience gained so far, it becomes clear that in addition to the parameters of the matrix and the parameters of the optical system of the camera, the parameters of the subject being captured also have a significant impact on the error and uncertainty. In a certain, unfavorable circumstances, their impact can be decisive.

Systematic examination of images in photogrammetric measurements should include the following several basic characteristics:

- brightness - difference in the gradation characteristics of the objects. It can be used for both monochromatic and color images.

- hue - relative brightness of the individual primary colors (hue) that determines the color of the objects. This feature defines the color in the Hue, Saturation, Luminance system (Hue, Saturation, Brightness). In many cases, the boundaries of objects cannot be successfully defined without taking into account the color. This characteristic is related to the spectral reflectance of different materials;

- texture - it characterizes the presence and type of a particular repeating fragment in the image. Texture is essential in interpreting the boundaries of objects made of different materials. The presence of the texture depends on the size of the identical objects that give rise to it and accordingly on the scale of the image. It allows to distinguish objects that cannot otherwise be defined, because they have close medium brightness and color tone with the surrounding background (practically blending with the background);

- form - basic form, configuration, outline is often enough as a single feature. For stereoscopically examined objects, height may be included;

- size - in the context of the scale of the image;

- model - the spatial arrangement of objects;

- shadows of objects, which are reflected in two aspects:

(a) the different shape of convex or concave portions of the object of measurement produces certain shadows that often interfere with the interpretation of the object's shape (even with identical brightness or spectral characteristics);

b) shadowing the boundaries of objects makes it difficult to interpret shadow contours. This is especially true for large-scale and large-scale image interpretation.

In addition to these characteristics, the following four surface types of material objects can be clearly defined and have an impact:

- orthotropic surfaces - reflect the incident flow uniformly in all directions - the so-called diffuse reflection; 
- mirror surfaces which reflect the incident flux in the plane of incidence and at an angle of reflection equal to the angle of incidence;

- rough (cut) surfaces that reflect mainly in the direction of the radiation source;

- combined surfaces having at least two maximums for reflecting the incident flux;

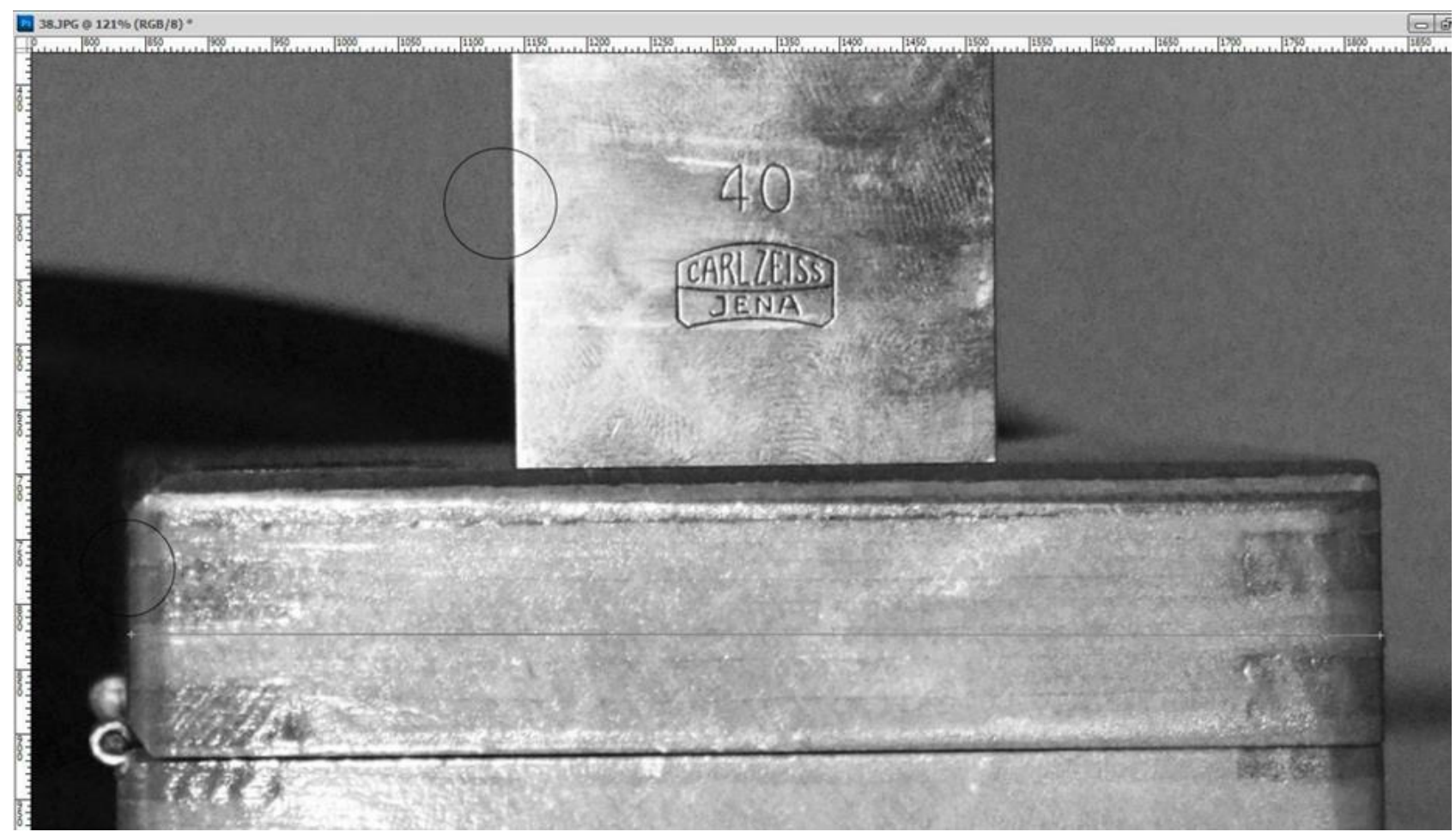

Fig. 2. Photo \# 1, rendered in black and white and enhanced with $100 \%$ contrast. The scale is increased to $121 \%$.

The most favorable for this type of measurements are the orthotropic surfaces, the most unfavorable are the mirrors (because of the frequently occurring highlights, which make it difficult to define the boundaries of the objects), but the most common surfaces are the combined ones.

The results of the experiments show that in the presence of poor focusing, combined with shading and large radii of curvature, the uncertainty is actually of considerable value (the measurement process is random), regardless of the processing of the photographs and the software used. The main reason is the subjective interpretation of the boundary of the object.

The results for well-focused images with highlights and texture indicate that it is more appropriate to bring the images in black and white and to increase the contrast by at least $100 \%$ - Figure 2. This processing process enhances the identification of shadows and radii of rounds, confirming the conclusion that, under ideal shooting conditions, the total measurement error involves describing a line in width or contour with a minimum of 3 px $(9.3 \mu \mathrm{m})-$ one real both neighbors. Under this assumption, the total measurement error under these conditions is limited to $\sim 9 \div 20 \mu \mathrm{m}$. For comparison, the upper limit of this error is less than the instrumental error of a linear-non-linear SI (caliper, caliper, altimeter and depth gauge) with a range of $360 \div 500 \mathrm{~mm}$, a constant of $0.02 \mathrm{~mm}$, which is $40 \mu \mathrm{m}$. The fact is that the total error in the types of calipers quoted is much greater.

These 3 pcs of CRT monitor - Samsung RGB Monitor RGB monitor with 1024x768 px resolution or LG Flatron E2242 LED (where one RGB dot has an approximate size of $0.2 \mathrm{~mm}$ ), as in the marker positioning process are ideally described by RGB dots with a width of $0.2 \mathrm{~mm}$ or:

$3 \mathrm{px}(9.3 \mu \mathrm{m})$ matrix $\rightarrow 600 \mu \mathrm{m}$ monitor $(3 \mathrm{px}$ from monitor);

$1 \mathrm{px}(3.1 \mu \mathrm{m})$ matrix $\rightarrow 200 \mu \mathrm{m}$ monitor $(1 \mathrm{px}$ from monitor).

The situation is the same with the LCD monitor of the laptop "HP 6830S" with a resolution of 1440x900 px, where an RGB dot has an approximate size - the same $\sim 0.2 \mathrm{~mm}(200 \mu \mathrm{m})$.

Taking into account the known fact that the visual resolution of a person with normal vision at a distance of $\sim 20 \mathrm{~cm}$ is $\sim 0.1 \mathrm{~mm}(100 \mu \mathrm{m})$, it can be observed from the measurements that the error varies but the maximum is $20 \mu \mathrm{m}(1 \mathrm{px})$ against the benchmark. This is the thickness of the stroke of the software marker displayed on the computer screen. That is, this can be taken as a total error of positioning (aiming) the start or end marker in the process of defining the measurement distance on the monitor.

2.2 Measurement errors using the Photogrammetric method. 
When using quality optics in the focal length range of 50 to $100 \mathrm{~mm}$, spherical and chromatic aberrations are within 2 px for the center of the frame, coma and astigmatism are virtually absent. This also applies to fixed focal length lenses in this range and to the center of the frame. In this situation, the main acting factor is the focus.

From Figure 3, "a" and "b" (f=100 mm), it is clear enough that at first glance, at normal magnifications, one line can be described in the worst case with 3 px, the reality, especially for non-metallic materials it is different.
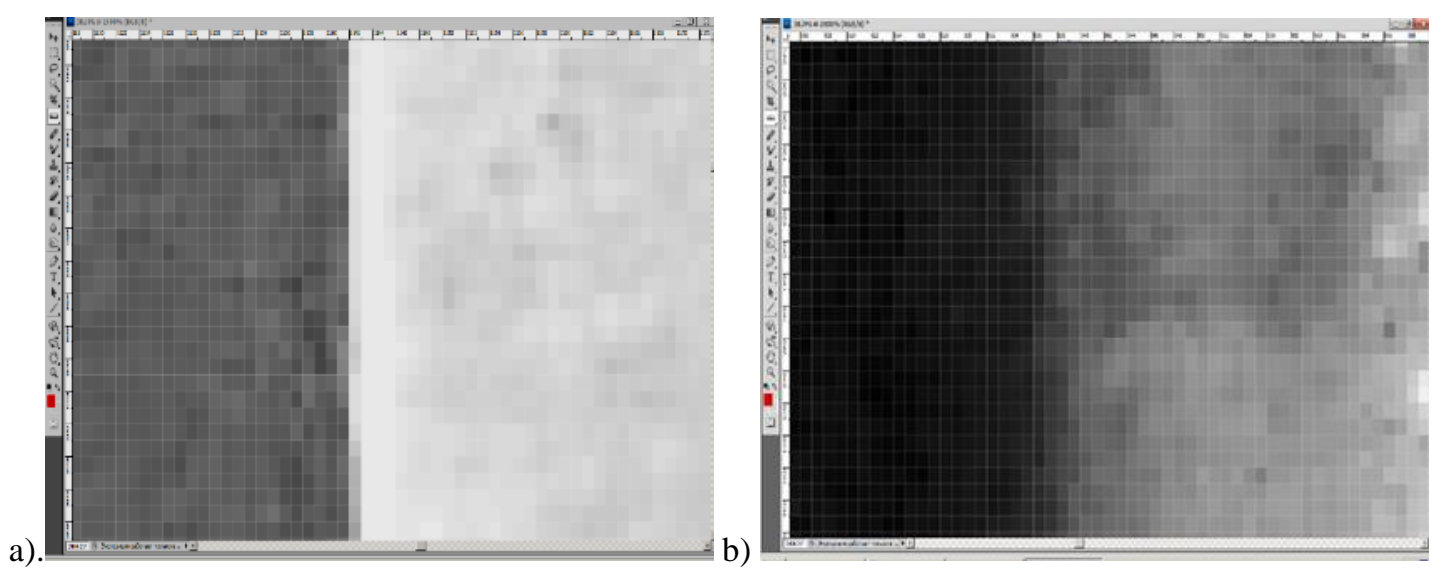

Fig. 3. a) A fragment from the boundary of a metal object enlarged 2400 times. b) A fragment from the boundary of a non-metallic object magnified 2400 times.

From Figure 1 it can be seen that in the case of mirrors or near mirror surfaces, in fact one line is described by 3 px. In the presence of a combination of orthotropic and rough surfaces, the situation is complicated. An experiment was conducted to clarify the influence of the focusing factor on average metal surfaces and the effect of the actual and extrapolated resolution of the photographic matrix.

An experimental study was carried out for the actual verification of the method, using a photograph taken at the metrology laboratory of the University of Rousse "Angel Kanchev", the department "Technology of machine building and machine tools", in which one metrological device was filmed - Complex two-profile inspection device gears (CTI). Photo taken for another study. The last test of the working ability of the method consists precisely in the use of photographs not taken specifically for this study. These pictures measure the dimensions that characterize the functional surfaces of the appliances, with sufficiently high accuracy and can be measured by reference contact methods to obtain their reference values. The reference values were obtained by measuring with digital micrometers with a constant of 1 $\mu \mathrm{m}$, which were previously verified. The results are shown in Figure 5.

Where there are differences between the dimensions measured by the Photogrammetric method and their reference values, the latter are indicated below the values measured by the Photogrammetric method. The photo in Figure 5 has its original resolution. The photo was taken with a Fujifilm FinePix camera used in the experiments above.

The measurement results are in person. It is important to note that all measured surfaces lie in the plane of the calibration size - this is the center plane of the CTI instrument. There are differences in Figure 5. the maximum differences are within $\sim 3 \div 4 \mu \mathrm{m}$, again in the "positive" direction.

This last check reinforces the view that the method is workable and accurate enough for heavy machinery purposes.

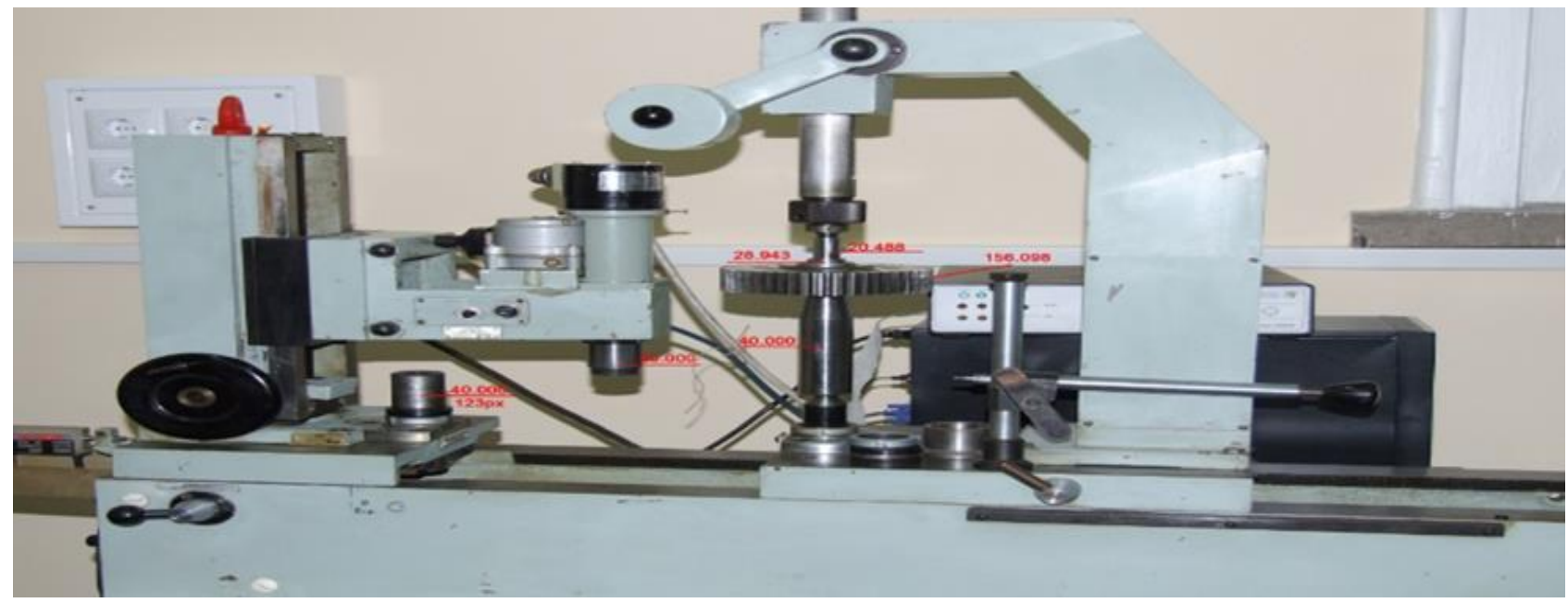

Fig. 4. Complex two-profile verification device (CTI). 


\section{Analysis of sources of uncertainty.}

\subsection{Extended Type B uncertainty in Photogrammetric measurements.}

According to the literature [1,5], the type B estimation of the mean square uncertainty is when we base on the available, a priori information about possible changes in the $\mathrm{X}$ value. If the upper $\mathrm{a}^{+}$and lower $\mathrm{a}^{-}$limits are symmetrically located then the uncertainty is calculated by dependence (1):

$$
U(x)=\frac{a}{\sqrt{3}}
$$

Extended uncertainty $U$ defines the interval around the measurement result. This uncertainty $U$ is obtained by assuming a normal distribution of the measured value and a sufficiently reliable root mean square uncertainty, $\mathrm{k}=2$ and a confidence interval probability of approximately 95\%. These conditions are fulfilled in most of the calibration cases used in photogrammetric measurements.

These conditions are fulfilled in most of the calibration cases used in photogrammetric measurements.

$$
\boldsymbol{y} \pm \boldsymbol{U}
$$

In the present case, when measuring large sizes, the most reliable postulate is the symmetrical arrangement of the upper and lower bounds of the size dispersion with respect to the reference value. In this situation, dependence (1) on the estimation of the root mean square uncertainty of type B is in force. As an example, in the worst case scenario, accumulation of all possible adverse factors analyzed in this chapter results in - $\max =200 \mu \mathrm{m}$.

Then if $\mathrm{a}_{\max }=200 \mu \mathrm{m}$, then $\mathrm{U}=115 \mu \mathrm{m}$ :

- In the average version, where - $\mathrm{a}_{\max }=60 \mu \mathrm{m}$, then $\mathrm{U}=34,6 \mu \mathrm{m}$.

- Ideally, subject to the measurement conditions analyzed in this article $-\mathrm{a}_{\max }=20 \mu \mathrm{m}$, then $\mathrm{U}=11.5 \mu \mathrm{m}$.

This root mean square uncertainty $[1,2]$ is commensurate (in one order) with the instrumental root mean square uncertainty of a digital micrometer with a range of $75 \div 100 \mathrm{~mm}$ and a constant of $\mathrm{i}=0.001$ (by passport). An example is the Mitutoyo micrometer with flat work surfaces of type 293-233-30 (digital), Ident. No. 7003314, Mitutoyo, Japan - U $=3 \mu \mathrm{m} \pm 10 \cdot 10^{-6} ; 1=3 \mu \mathrm{m} \pm 10 \mu \mathrm{m}$, according to SK No. H046 DKD-K-14501 / 08.2007 - Calibration Laboratory for Measurements - Mitutoyo.

In fact, the uncertainty budget is a tabular representation of the uncertainty component of the measurement result. It shall include a list of all sources of uncertainty, the associated root mean square uncertainty and the methods for estimating it. It is important to note that in the table the corresponding value is represented by the standard uncertainty as well as the sensitivity coefficient $\mathrm{C}_{\mathrm{i}}[3]$.

The uncertainty budget presentation is shown in Table 1. The quantities involved in the determination of the uncertainty budget are estimated, as already indicated, on the basis of expert analysis of the influencing factors. The reason for using this method is the scarce information that is published on the subject. The disclosure of the main sources

\begin{tabular}{|c|c|c|c|c|c|c|c|}
\hline 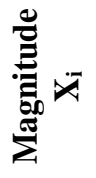 & 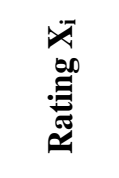 & 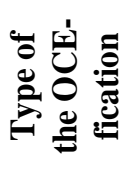 & 窇 & 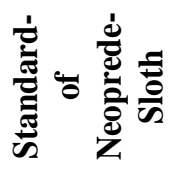 & 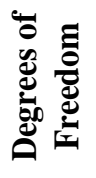 & 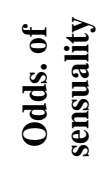 & 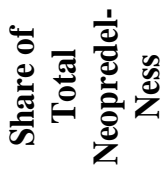 \\
\hline $\mathrm{X}_{1}$ & $9.3 \mu \mathrm{M}$ & In & evenly & $1.8 \mu \mathrm{M}$ & $\infty$ & 1 & $1.8 \mu \mathrm{M}$ \\
\hline $\mathrm{X}_{2}$ & $60 \mu \mathrm{M}$ & $\mathrm{B}$ & Evenly & $34.6 \mu \mathrm{M}$ & 2 & $1 / 2 x \sqrt{2}$ & $2.2 \mu \mathrm{M}$ \\
\hline$X_{3}$ & $9.3 \mu \mathrm{M}$ & In & Evenly & $1.8 \mu \mathrm{M}$ & $\infty$ & 1 & $1.8 \mu \mathrm{M}$ \\
\hline \multirow[t]{2}{*}{$\mathrm{X}_{4}$} & $20 \mu \mathrm{M}$ & In & Evenly & $11.5 \mu \mathrm{M}$ & 2 & 1 & $11.5 \mu \mathrm{M}$ \\
\hline & & & & & & & $11.8 \mu \mathrm{m}$ \\
\hline
\end{tabular}
of type B uncertainty can be categorized in several directions - Table. 1.

Table 1. Uncertainty budget for photogrammetric measurements.

- Object of measurement - $X_{1}$ - the results of the experiments show that in the presence of poor focusing combined with shading and large radii of reflection, in the case of mirror-reflecting and combined reflecting surfaces, the uncertainty is indeed of considerable value (the measurement process is random), regardless of photo processing and software used.

The main reason is the subjective interpretation of the boundary of the object. In normal subjects and shooting conditions, the total measurement error involves describing a contour line in width or contour with a minimum of 3 px from the matrix $(9.3 \mu \mathrm{m})$ - one real and both adjacent - Figures 1 and 2.

- Measurement (and calibration) procedure - $\mathrm{X}_{2}$ - for large sizes up to $5000 \mathrm{~mm}$ combined with small calibration dimensions - $10 \div 20 \mathrm{~mm}$ uncertainty is quite high - experimental studies show. Here the main influence is due to the 
small values in pixels of the calibration against the background of the large dimensions of measurement. Other main causes are poor autofocus, poor subject illumination, vibration during exposure, and more. which are distributed according to a uniform law. Subject to the normal procedure for recording, normal calibration and accumulation of all other extreme, adverse factors, the uncertainty determined experimentally is within $\pm 60 \mu \mathrm{m}$ at $\mathrm{k}=2$.

- Measurement Instrument (MI) - $\mathrm{X}_{3}$ - The interesting point here is that the measuring instrument overlaps to some extent with the operator and the software. For the hardware the operator is working on - 3 pc on the monitor (CRT RGB monitor "Samsung - SyncMaster 795DF or LSD LED - LG Flatron E2242) in the process of marker positioning is ideally described by RGB points with a width of $\sim 0.2 \mathrm{~mm}$ or:

$3 \mathrm{px}(9.3 \mu \mathrm{m})$ matrix $\rightarrow 600 \mu \mathrm{m}$ monitor $(3 \mathrm{px}$ from monitor);

$1 \mathrm{px}(3.1 \mu \mathrm{m})$ matrix $\rightarrow 200 \mu \mathrm{m}$ monitor (1 px from monitor);

The series of experiments were performed on the LCD monitor of the laptop "HP 6830S", with one RGB dot having an approximate size of the same $\sim 0.2 \mathrm{~mm}(200 \mu \mathrm{m})$.

Taking into account the known fact that the visual resolution of a person with normal vision at a distance of $\sim 20 \mathrm{~cm}$ is $\sim 0.1 \mathrm{~mm}(100 \mu \mathrm{m})$, it can be observed that the error varies but the maximum is $200 \mu \mathrm{m}$ from the monitor ( $1 \mathrm{px}$ of monitor matrix) relative to the reference value. This is the thickness of the software marker bar displayed on the computer screen and perceived by the operator. Or to put it another way, it can be taken as the total uncertainty of positioning the start or end marker in the process of defining the distance to be measured on the monitor (similar to measurements on instrumental or universal microscopes and projectors) and transferred and designed on the matrix (photo) with a value of $9.3 \mu \mathrm{m}$ or $3 \mathrm{px}$ in the worst case.

- Environment - $\mathrm{X}_{4}$ - The most serious environmental impact is the brightness and quality of the matrix and the optical system of photographic equipment. Due to the good illumination (if necessary, illumination is provided in order to better show the clear contour boundary of the subject), the contour boundaries of the subject are clearly displayed and normal operation of the autofocus system is ensured, which as we have already seen always works at a satisfactory level - Figure 2. Under these conditions, the total measurement uncertainty is limited to $20 \mu \mathrm{m}$ as a typical value.

Table 1 shows that illumination and quality of the photographic technique have the most significant share in the measurement uncertainty budget.

It should be borne in mind that incorporating the quality of the camera's optical system into external conditions is not a mistake, but a deliberate act of analysis. The method is applicable to all types of optical systems - both high quality and high cost and medium quality ones (smartphones and GSM). In this situation, it is incorrect to integrate the quality of the phototechnics and the optical system with the measuring instrument - MI. Its logical place is in the external environment, the more so that the quality of the picture depends very much on the brightness.

The calculation of the standard measurement uncertainty in the absence of correlation of input values is performed by the dependence of:

$$
U(x)=\sqrt{\sum_{i=1}^{m} U_{i}^{2}}(x)=\sqrt{U_{1}^{2}} \cdot C_{1}^{2}+U_{2}^{2} \cdot C_{2}^{2}+U_{3}^{2} \cdot C_{3}^{2}+U_{4}^{2} \cdot U_{4}^{2}=11,8 \mu m
$$

Or

$$
Y=y \pm 0.0118 \mathrm{~mm}
$$

Practice shows that uncertainty is neither a criterion for the purchase of the measuring instrument, nor for its actual operation, but rather a parameter related to the theoretical, accurate interpretation of the measuring instrument and the result of the measurement, and for attestation and validation of such a measurement method.

In this case, the decisive parameter is the measurement error.

The sources of error and uncertainty have been identified by expert analysis. All the experiments conducted so far prove the experts' general opinion that it is the "method error" that is the most important indicator of interest to consumers, which proves the appropriateness of the experimental studies carried out.

Attention should be paid to measuring results at values close to the limit values of error intervals or uncertainties.

\section{Conclusion}

As a conclusion from the study, the following fact can be summarized: As expected when measuring large sizes using the Photogrammetric method, uncertainty looks a lot different than what is presented in popular scientific literature.

The perespective distortions in the different planes and the inherent errors of the optical system lead to serious measurement errors.

And while for small sizes in large structures, these errors are in the order of $10 \div 20 \mu \mathrm{m}$, in the case of large sizes of large structures they can reach $100 \div 200 \mathrm{~mm}$.

It is for this reason that the technology and software that make use of this variant of the large and very large size method are extremely expensive in our conditions.

Future plans for continuing the study in the field involve the preparation of a methodology for carrying out controls and measurements through the Photogrammetric method in the heavy machinery industry. 


\section{Acknowledgments}

In conclusion, I would like to thank Associate Professor PhD Eng. Boris Sakakushev, as well as the other employees of the Department of Technology of Mechanical Engineering and Cutting Machines at the University of Ruse "Angel Kanchev" for the detailed review of the draft note and made critical comments and valuable recommendations. I would also like to thank Prof. PhD Eng. Plamen Daskalov from "Angel Kanchev" University of Ruse for his assistance, assistance and support in financing my participation in DAAAM - 2019.

The study was supported by contract of University of Ruse "Angel Kanchev", № BG05M2OP001-2.009-0011-C01, "Support for the development of human resources for research and innovation" at the University of Ruse "Angel Kanchev". The project is funded with support from the Operational Program "Science and Education for Smart Growth 2014 - 2020" financed by the European Social Fund of the European Union.

\section{References}

[1] Sakakushev B., V. Grigorov, T. Todorov. Transformation coefficient and analysis of the measurement error by the photogrammetric method in mechanical engineering. "News of the Union of Scientists - Rousse", 1/2011. Technical Sciences Series, 2011, Issue 5, ISSN 1311-106X.

[2] Георгиев, Г.; Анализ на факторите, влияещи върху неопределеността при измерване на геометрични параметри на детайли чрез фотограметричния метод; „Техника и технологии“ - Ямбол, Тракийски университет, Стара Загора, 2016 г.

[3] Радев, Х.; Метрология и измервателна техника - книга - справочник в три тома под общата редакция на Христо Радев, том 1, Софтрейд, София, 2008, ISBN 978-954-334-077-4.

[4] Георгиев, Г.; Сакакушев, Б.; Георгиева, К.; Изследване на приложимостта на фотограметричния метод за измерване на много малки размери; Научни трудове на Русенския университет -2015 , том 54, серия 2.

[5] Сакакушев, Б.; Измервателни системи - теория и практика - Монография, Национален военен университет, Долна Митрополия, 2019 г., 118 стр. ISBN 978-954-713-129-

[6] Sakakushev B., S. Parvanov, Tz. Gueorguiev. The Real Capabilities of the Photogrammetric and the Stereophotogrammetric Methods for Measurement in Mechanical and Manufacturing Engineering.// Proceedings of SOCIOINT 2018- 5th International Conference on Education, Social Sciences and Humanities, 2-4 July 2018Dubai, U.A.E., 2018, No 1, pp. 108-114, ISSN 978-605-82433-3-0.

[7] Сакакушев Б. Б., Г. К. Георгиев, И. С. Железаров. Первые шаги для построения бюджета неопределености при фотограмметрических измерениях в машиностроении.// Information Processing Systems, 2015, брой 2, стр. 54-57, ISSN ISSN 1681-7710.

[8] Sakakushev B., M. Karshakov, T. Todorov. Application of the Photogrammetric Method for Measurement in Mechanical Engineering. "Proceedings of the Union of Scientists - Rousse", Series "Technical Sciences", 2009, Issue 5, pp. 20 - 24, ISSN 1311-106X. 